\title{
INFLUENCE OF THE SUBSTRATE ON THE ELECTRICAL PROPERTIES OF THICK-FILM RESISTORS
}

\author{
A. CATTANEO and L. PIROZZI \\ F. I. Magneti Marelli, Systems and Electronics Division, 27100 Pavia, Italy \\ B. MORTEN and M. PRUDENZIATI \\ Istituto di Fisca dell'Università, Laboratorio di Elettronica, 41100 Modena, Italy
}

(Received July 20, 1979)

\begin{abstract}
The effect of substrate type on the electrical properties of thick film resistors is determined. Five different substrates are used. The following properties are investigated: - thermal expansion, resistor profiles, resistance, TCR and resistor gauge factor. The resistors are physically inspected using X-ray diffractometry and electron probe analysis. This paper shows that conduction mechanism models for thick-film resistors generally need not take into account chemical and structural interactions with the substrate. However the effect of substrate on TCR values is significant for resistors exhibiting a large piezoresistive effect.
\end{abstract}

\section{INTRODUCTION}

Recent papers ${ }^{1,2}$ attribute the conduction mechanism in thick-film resistors to percolative tunneling of electrons through conductive grains embedded in the glassy matrix of the resistive layer. This model assumes that the resistance of percolation paths dominates the resistance of a resistor network, electrically equivalent to the thick-film resistor where each resistor is made by a very thin dielectric layer through which the electrons flow by tunneling effect. ${ }^{3}$ It has been shown ${ }^{4,5}$ that experimental results on $\mathrm{Ru}$-based thick-film resistors screen-andfired on $96 \% \mathrm{Al}_{2} \mathrm{O}_{3}$ substrates closely fit the proposed model. However, more recently it has been pointed out ${ }^{2}$ that thick-film resistors can be characterized by a piezoresistive effect with a nonnegligible value of the "gauge factor" (in the order of 10). This suggests that the thick-film resistor electrical properties (resistance and, particularly, its temperature coefficient) depend on the mismatch between the thermal expansion coefficient of the film and that of the substrate. Although the paste manufacturers claim that their compositions are properly prepared to fit the thermal expansion coefficient of $96 \% \mathrm{Al}_{2} \mathrm{O}_{3}$ substrates, all hybrid circuit manufacturers have found that reproducibility is not easily obtainable because of differences in the glass content in pastes of the same series with different nominal sheet resistivity. This is because of sensitivity of the paste to the firing profile, in particular to cooling. On the other hand, the model of conduction mechanism, that has been quoted above, does not take into account any interaction between the substrate and the resistor film. In order to verify whether or not and in which way the substrate characteristics must be considered in the conduction mechanism of thick-film resistors, this paper describes the piezoresistive effect and the electrical properties of thick-film resistors screen-andfired on five different types of substrates characterized by different thermal expansion coefficients.

\section{MATERIALS AND EXPERIMENTAL METHODS}

The film resistors were ob tained by using a commercially available and widely used Ru-based composition (DP 1400 series). The films were fired under a strictly-controlled identical profile on the following set of substrates:

$$
\begin{aligned}
& \text { - } 99 \% \text { beryllia } \\
& \text { - } 96 \% \text { alumina } \\
& \text { - steatite Alsimag } 35 \text { (type A) } \\
& \text { - steatite Alsimag } 665 \text { (type B) } \\
& \text { - yttria stabilized zirconia }
\end{aligned}
$$


Silver-free terminations were provided to all resistors in order to avoid metal migration effects. ${ }^{5}$ In order to correlate the electrical properties of the resistors to the substrate characteristics the following measures and analyses were performed

- thermal expansion coefficients of the used substrates in the range $-50^{\circ} \mathrm{C}$ to $+150^{\circ} \mathrm{C}$

- resistor thickness profiles

- resistances

- temperature coefficients of resistance (TCR)

- resistor gauge factors (GF)

- resistor X-ray diffractometry

- resistor electron microprobe analysis

\section{EXPERIMENTAL RESULTS AND DISCUSSION}

Figure 1 shows the measurements of linear thermal expansion, $\Delta l / l$, for the different types of substrates in the range $-50^{\circ} \mathrm{C}$ to $+150^{\circ} \mathrm{C}$ taken using a PERKIN-ELMER dilatometer, mod. TMS2.

Neither new phases, differences of relative intensities in the peaks of the resistor main constituents (bismuth ruthenate and silicate) nor grain size variations were detected by X-ray diffractometry of resistors screen-and-fired on the different substrates. Moreover, the electron microprobe analysis did not indicate any dissolution of new elements from the substrate into the resistors. It can
TABLE I

Normalized sheet-resistivity at room temperature.

\begin{tabular}{lllll}
\hline $\mathrm{BeO}$ & $\mathrm{Al}_{2} \mathrm{O}_{3}$ & Steatite 665 & Steatite 35 & $\mathrm{ZrO}_{2}\left(\mathrm{Y}_{2} \mathrm{O}_{3}\right.$ \\
1,006 & 1,000 & 1,040 & 1,004 & 1,050 \\
\hline
\end{tabular}

be concluded that no chemical interaction takes place between the used paste composition and substrates. However, the thickness profiles checked by Talysurf, mod. 10 show that the substrates present a different wettability. In zirconia substrates, for instance, films deposited through the same mask tend to be less wide, but deeper than films deposited on $96 \% \mathrm{Al}_{2} \mathrm{O}_{3}$. The results in Table I fully take this effect into account. It shows the sheet resistivity, normalized to $96 \% \mathrm{Al}_{2} \mathrm{O}_{3}$ substrates, measured at room temperature.

It is seen that the sheet resistivity is not influenced, in practice, by the different type of substrate: all the measured values are in the range $5 \%$ of the reference value.

Figure 2 shows the film resistance, normalized to the minimum measured value vs. temperature. A change in $T_{\min }$, the temperature corresponding to the minimum resistance value $R_{\min }$, is observed by changing the substrate material. It is seen that $T_{\min }$ shifts towards lower temperatures as the thermal expansion coefficient of the substrate increases. As shown in Figure 3, it was also found that TCR increases by increasing the expansion coefficient.

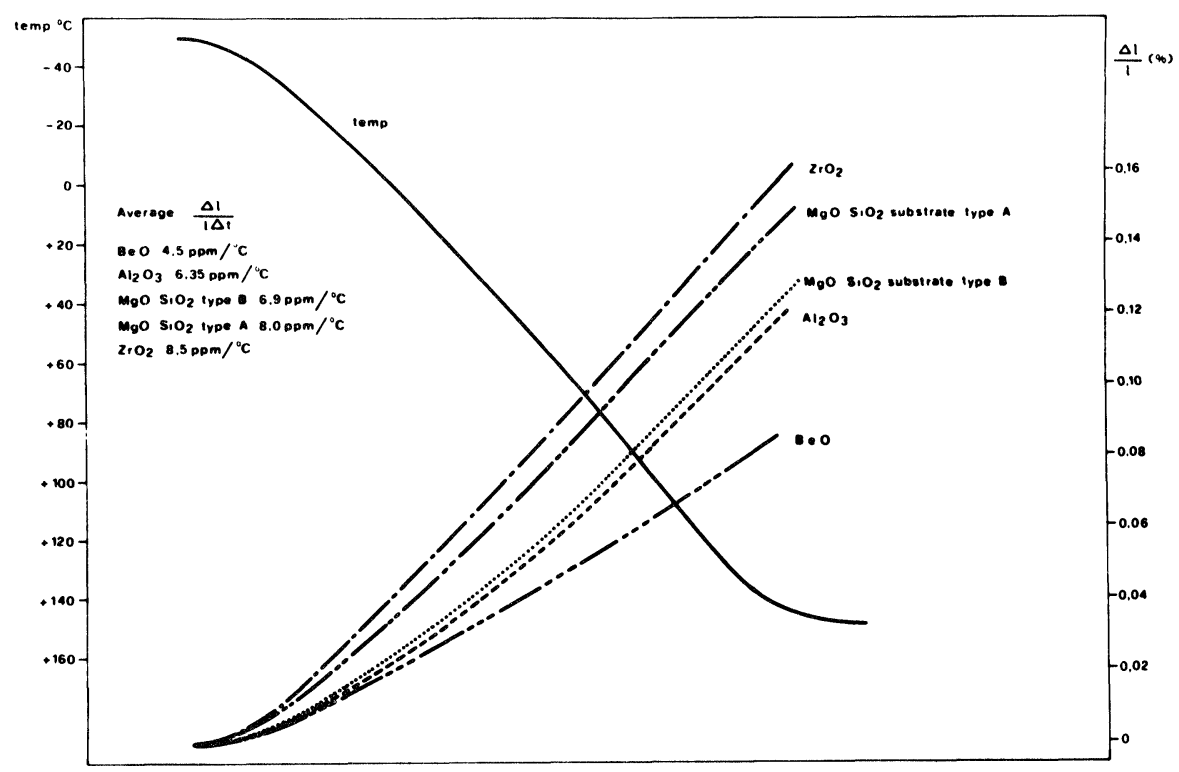

FIGURE 1 Curves of linear thermal expansion, $\Delta l / l$, for different ceramic substrates, versus temperature. 


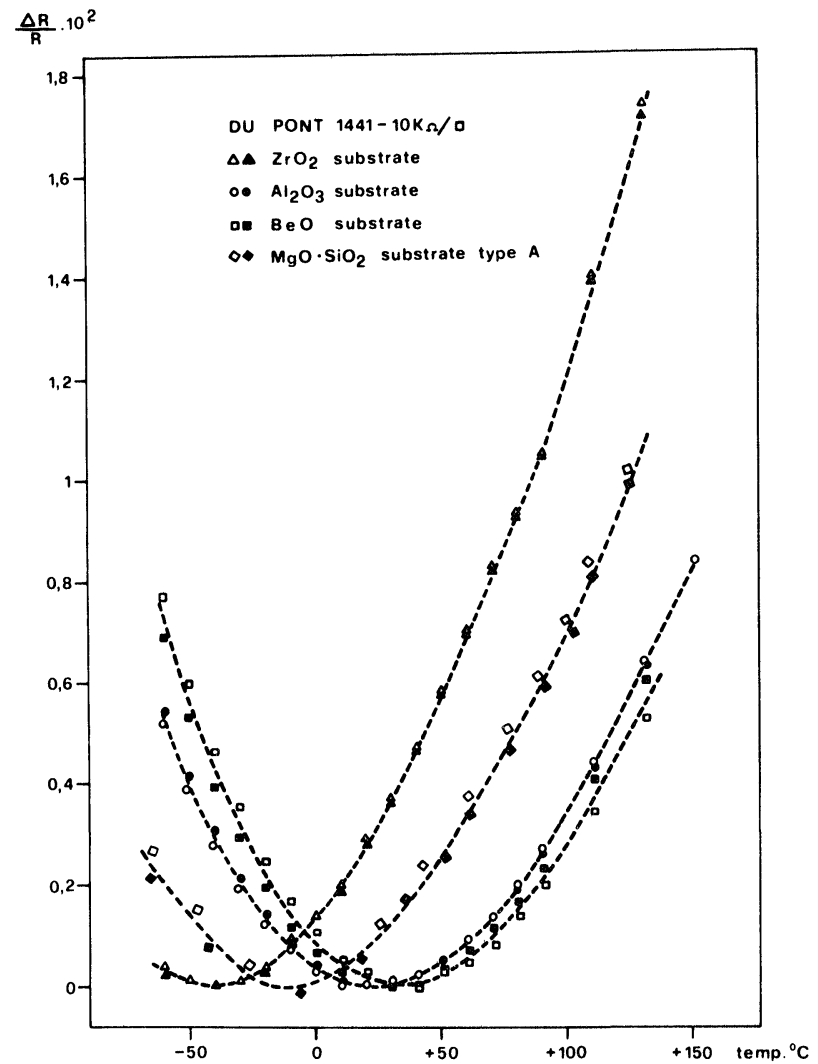

FIGURE 2 Normalized resistance $v s$. temperature for DP 1400 resistors, screen-and-fired on different types of substrate.

Because X-ray and microprobe analyses have shown that no chemical and structural interaction takes place between the film and the substrate, the observations reported in Figure 2 and in Figure 3 can be explained only in terms of thermal expansion mismatch between the resistive layer and the substrate. In other words, the piezoresistive effect plays its rôle because of the stress applied to the resistors by the substrate. In fact, it is known ${ }^{7}$ that the TCR of a film characterized by a certain thermal expansion coefficient, $\alpha_{f}$, and deposited on a substrate with thermal expansion coefficient $\alpha_{s}$ is

$$
\mathrm{TCR}=\mathrm{TC} \rho-\alpha_{f}-\frac{2\left(\alpha_{f}-\alpha_{s}\right)(\mathrm{GF}-1-\gamma)}{1-\gamma}
$$

where TC $\rho$ indicates the temperature coefficient of the resistivity, GF is the longitudinal gauge factor of the film and $\gamma$ is Poisson's modulus of the substrate.

The analyses performed on the films, either with $\mathrm{X}$-rays and/or with electron microprobe, give rise to

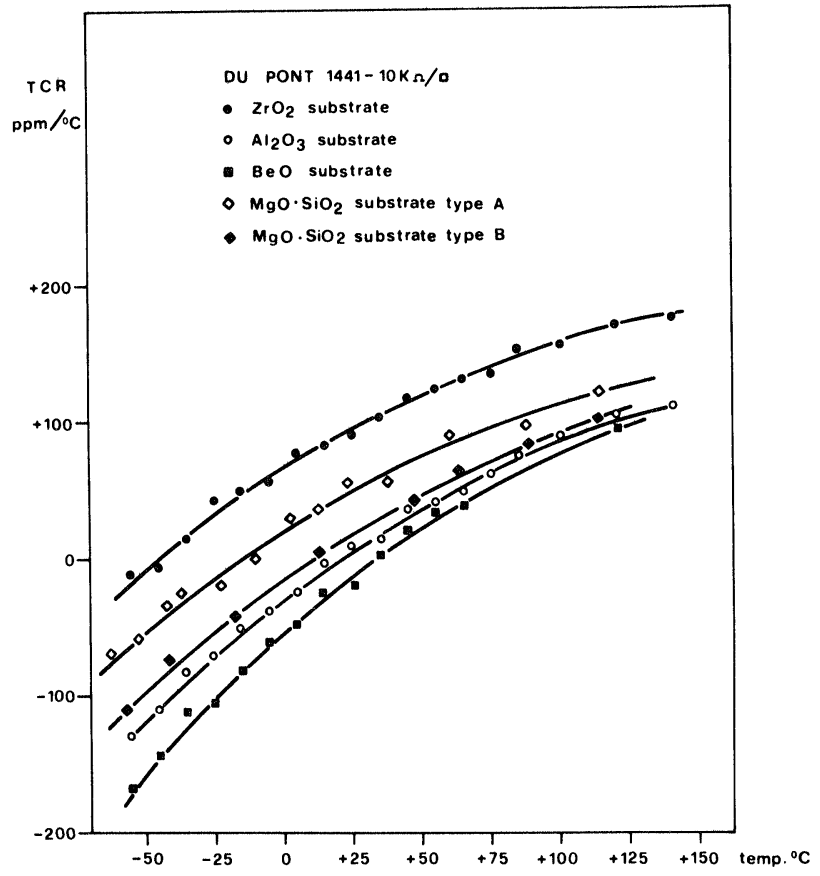

FIGURE 3 Experimental TCR values for DP 1400 series resistors screen-and-fired, on different ceramic substrates.

the conclusion that in the present case $\mathrm{TC} \rho$ and $\alpha_{f}$ do not change with changing substrate. Both parameters depend on the chemical and structural composition of the film that remains unchanged. Then, TCR's measured on two different substrates can be related one to one another by

$$
\mathrm{TCR}_{1}-\mathrm{TCR}_{2}=\frac{2\left(\alpha_{s 1}-\alpha_{s 2}\right)}{1-\gamma}(\mathrm{GF}-1-\gamma)
$$

It has been verified that Poisson's modulus is about the same for the set of substrates considered in this paper.

Having measured the longitudinal gauge factor by cantilever technique, ${ }^{8}$ being $\gamma=0.22$ and knowing $\alpha_{\mathrm{s}}$ values as given in Figure 1, TCR's can be calculated by taking $96 \% \mathrm{Al}_{2} \mathrm{O}_{3}$ substrate as the reference. The good fit of the experimental results to this calculation is shown in Figure 4 and in Figure 5 where paste with a nominal sheet resistivity of $10 \mathrm{kohm} / \square$ was used. It has been verified that the fitting holds also for pastes with $1000 \mathrm{ohm} / \square$ and $100 \mathrm{kohm} / \square$ nominal sheet resistivity.

Obviously, the resistors screen-and-fired on the different types of substrates are subjected to different stresses also at room temperature. The change in sheet resistivity induced by these stresses can be 


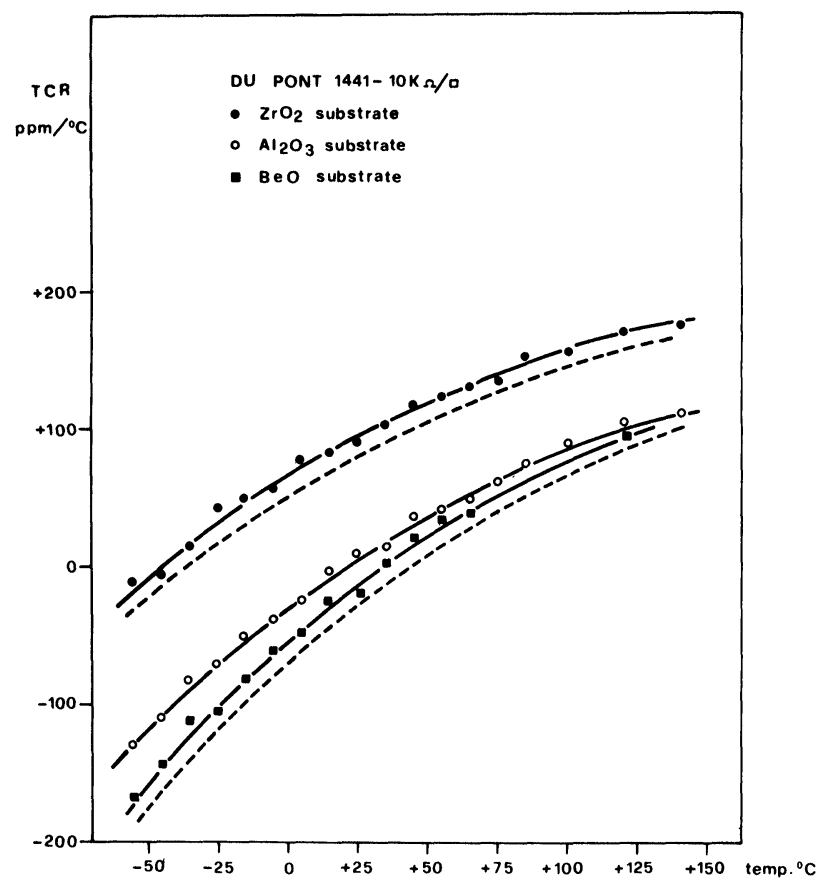

FIGURE 4 Experimental (continuous lines) and calculated (dotted lines) TCR values for DP 1441 resistors screen-andfired on zirconia, alumina and beryllia substrates.

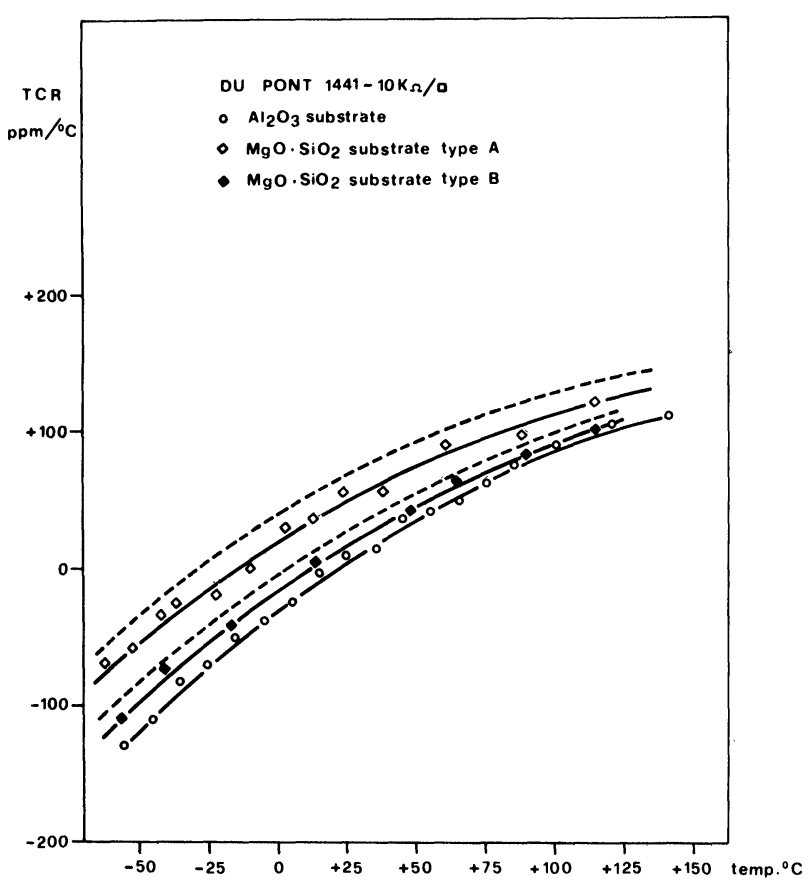

FIGURE 5 Experimental (continuous lines) and calculated (dotted lines) TCR values for DP 1441 resistors screen-andfired on steatite Alsimag 35 and steatite Alsimag 665. evaluated by integrating Eq. (1) with the following result.

$$
\Delta R / R=\Delta T \frac{2\left(\alpha_{s 1}-\alpha_{s 2}\right)}{1-\gamma}(\mathrm{GF}-1-\gamma)
$$

where $\Delta T$ is the difference between the peak firing temperature and room temperature. It is easily seen that $\Delta R / R$ is lower than $2 \%$ for the different substrates used here, in agreement with the experimental values reported in Table I.

\section{CONCLUSION}

In conclusion, this paper shows that in the investigation of conduction mechanisms in thick-film resistors, models of electron transportation can be conceived disregarding the chemical and structural interactions with the substrate. However, if these models aim to explain the unusual behaviour of TCR $v s$. temperature, ${ }^{1}$ the effect of the substrate must be taken into account through Eq. (1), especially in the case where the resistor exhibits a significantly large piezoresistive effect as in resistors made with Ru-based paste composition. On the contrary, all the models proposed up to now underevaluate this fact. These models assume that the thermal expansion coefficients of the resistive layer and of the substrate are the same, making the last term in Eq. (1) vanish. This assumption is consistent with the claim of the paste manufacturers if $96 \% \mathrm{Al}_{2} \mathrm{O}_{3}$ substrates are used. However, it is well known that this is only a first approximation, acceptable for technological applications, but to be used with caution when investigations on conduction mechanisms are made.

\section{ACKNOWLEDGMENTS}

The authors are indebted to Prof. C. Canali for assistance and suggestions, to Prof. F. Forlani for the help given in the interpretation and correlation between the collected data and to Dr. Celotti for assistance in X-ray measurements.

\section{REFERENCES}

1. F. Forlani and M. Prudenziati "Electrical conduction by percolation in thick-film resistors" Electrocomp. Sci. Technol. 3, 77 (1976).

2. Pike and Seager, "Electrical properties and conduction mechanism of Ru-based thick-film (Cermet) resistors" J. Appl. Phys. 48 (12), Dec. 1977.

3. J. W. M. Biesterbos, "Structure and D.C. electrical properties of a $\mathrm{Au}-\mathrm{Ru}-$ glass thick-film systems" J. Appl. Phys. 45, 153 (1974). 
4. M. Prudenziati, "On the temperature coefficient of resistivity in thick-film resistors and the percolation model" Alta frequenza, 46, 287-147 E (1977).

5. A. Cattaneo, F. Forlani, M. Cocito, and M. Prudenziati, "Influence of the metal migration from screen-and-fired terminations on the electrical characteristics of thick-film resistors." Proc. European Hybrid Microelectronics Conf. Bad Homburg, 2-4 May 1977.

6. M. Prudenziati and U. Costa, Proprietà e meccanismo di conduzione in resistori Cermet a base di $\mathrm{Ru} \mathrm{O}_{2}$, A.E.I. 1977.
7. B. S. Verma and S. K. Sharma, "Effect of thermal strains on the temperature coefficient of resistance," Thin Solid Films 5 (1970) R44-R46; B. Morten, L. Pirozzi, M. Prudenziati, and A. Taroni, Strain sensitivity in film and Cermet resistors: measurable and physical quantities, unpublished.

8. Timoshenko, Strength of Materials, Vol. I, Van Nostrand. 

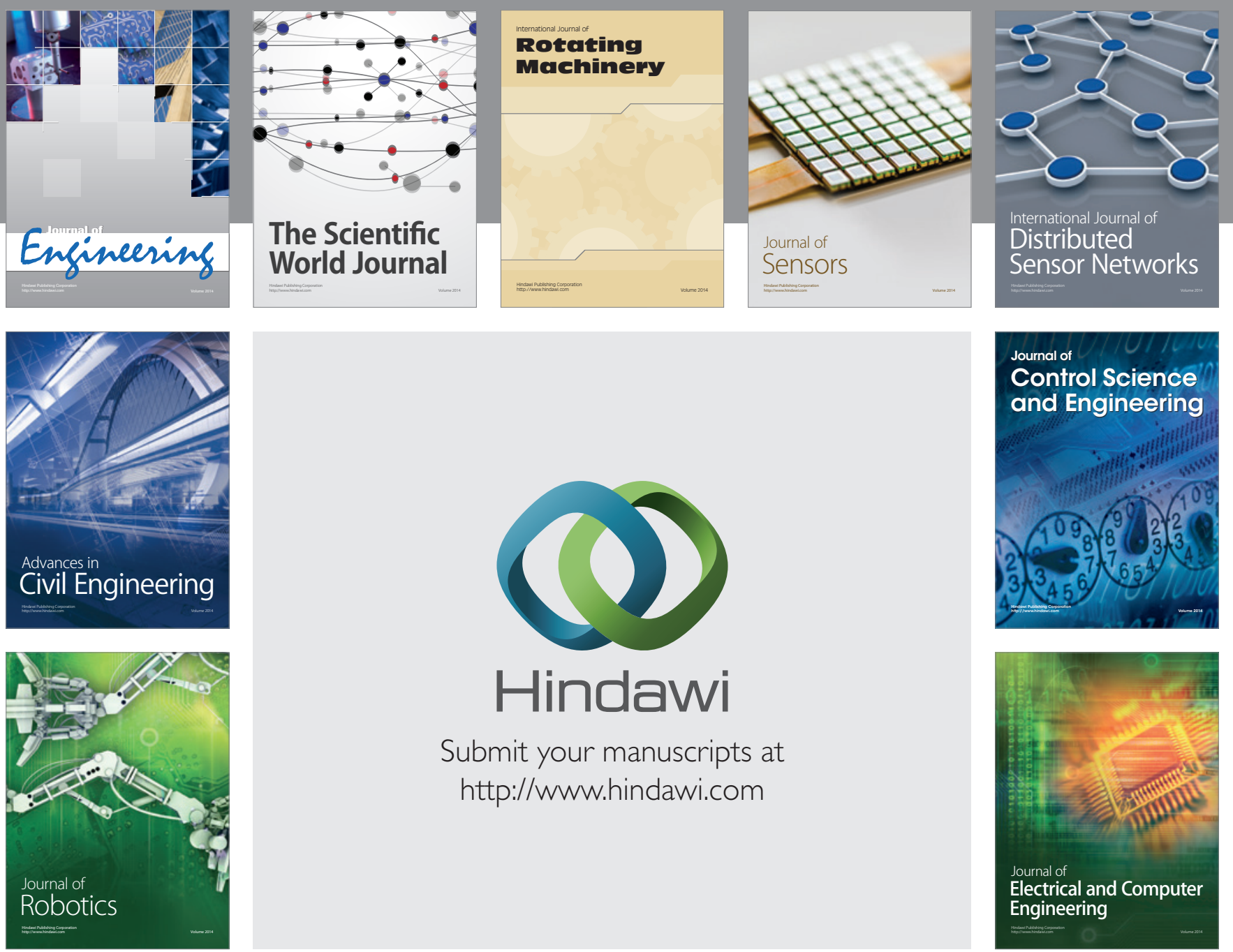

Submit your manuscripts at

http://www.hindawi.com
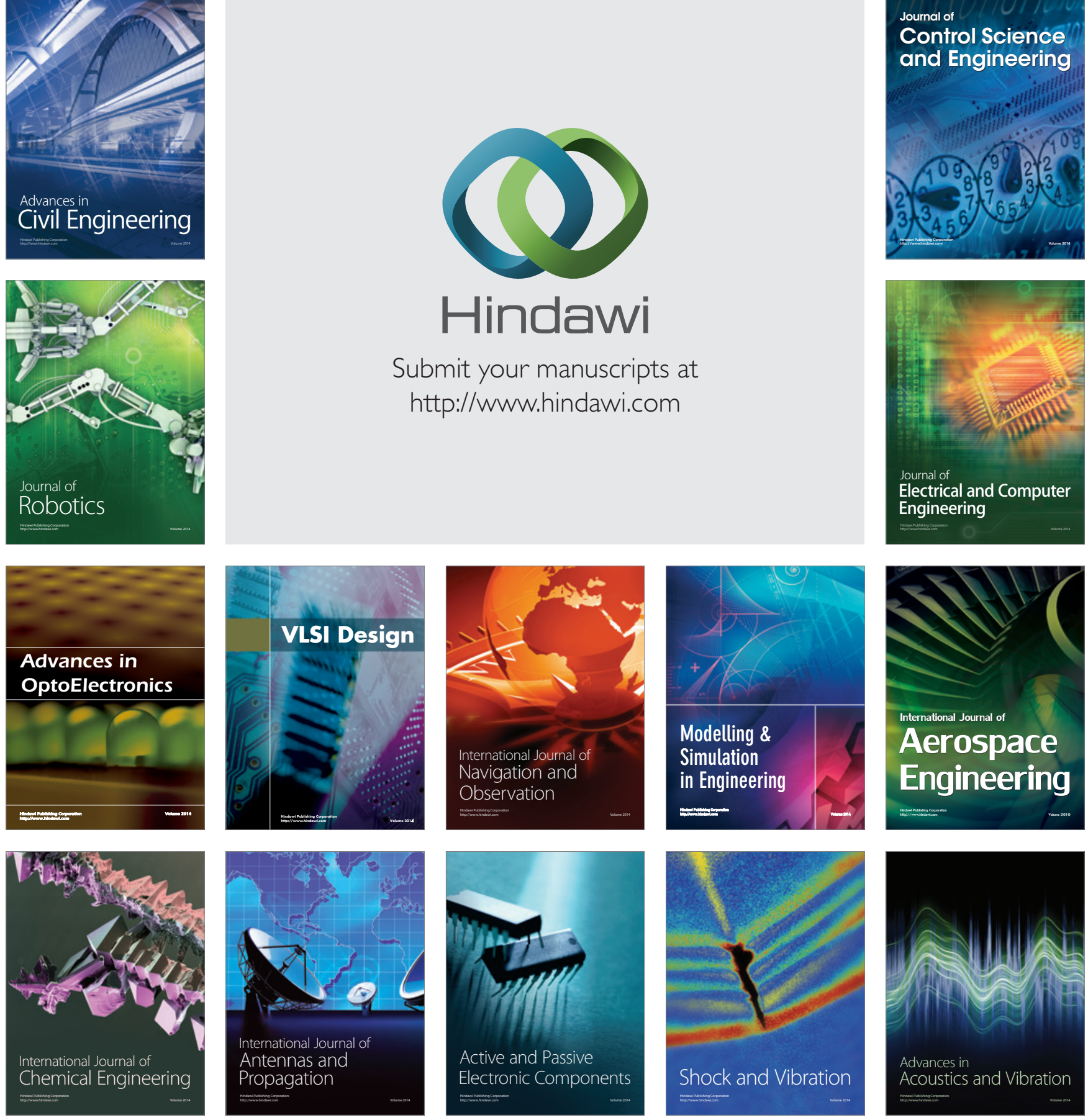